\title{
USING ENGLISH ONLY IN THE SOUTH AFRICAN ENGLISH CLASSROOM?
}

Gary P. Barkhuizen

Decisions made about language choice in educational settings are not easy to make: teaching contexts throughout the country are very different, and massive changes in the national language and language-in-education policies have taken place. The inherent power of English and attitudes to all South African languages are also determining factors. This article examines the place of home languages other than English in the English classroom in South Africa. Contextual factors for considering the English only/home language issue are presented. The attitudes of student English teachers with regard to the use of the home language in their future English classes are then examined. This exploratory study reveals a difference in attitude towards the acceptability of home language use between teachers who are themselves English speakers and those who are not.

Besluite oor taalkeuse in die onderwys is 'n moeilike saak weens die konteksverskille in die land. Groot beleidsveranderinge op nasionale vlak en t.o.v. taal in die onderwys het plaasgevind. Die inherente mag van Engels en houdings teenoor alle Suid-Afrikaanse tale is verdere bepalende faktore. Hierdie artikel ondersoek die plek van 'n ander huistaal as Engels in die Engels-klaskamer in Suid-Afrika. Kontekstuele faktore vir die oorweging van Engels as enigste taal/huistaal word gebied. Die houdings van studente-Engelsonderwysers t.o.v. die gebruik van huistaal in hul toekomstige Engels-klasse word ondersoek. Hierdie verkennende studie toon 'n houdingsverskil teenoor die aanneemlikheid van huistaalgebruik tussen onderwysers wat self Engelssprekend is en dié wat nie is nie.

\section{INTRODUCTION}

The place of a home language (HL) other than English in the English classroom has been debated for some time now, especially in the context of language teaching methodology (e.g. the grammar-translation method versus the direct method; see Richard \& Rodgers, 1986), and more recently in the context of second language acquisition theory (e.g. Krashen, 1981, 1982) and postmodern educational theory (Auerbach, 1993; Peirce, 1995). In South Africa the debate is gaining momentum: recent national conferences have included numerous presentations dealing with the English only issue (usually framed within medium of instruction and codeswitching arguments), and the media and academic publications have also been responsible for bringing the issue of language choice in educational settings into the open. 
No doubt this interest has been stimulated by the vast political and educational reforms that have taken place in the country in recent years, which in turn have led to the restructuring of the nation's language policy, and particularly the language-in-education policy. The gist of these policies is that all South African languages should have equal status, nobody should be discriminated against in any way on the grounds of language choice, and multilingualism should be perceived as a national resource that is an integral part of nation building and the creation of access (ANC, 1994; Heugh, 1992, 1993).

Unfortunately, much of the debate concerning the use of the HL in English classrooms is unclear. Arguments often start with 'It depends.' Well, what does it depend on? This is also difficult to answer, especially if one does not know what 'English only in the English classroom' really means. In fact, the statement is dangerously confusing unless one exactly defines the context in which questions about $\mathrm{HL}$ versus the use of English only are asked.

\section{CONTEXTUAL FACTORS IN THE ENGLISH ONLY DEBATE}

A description of contextual factors involves examining the relationship between language use inside and outside the classroom. It also involves looking at the structural make-up of the classroom, especially in terms of who the class members are and what languages they speak, and the nature of language learning/teaching activities which occur in the classroom. The following perhaps begins to describe some of these factors. It consists of a list of paired, and sometimes contrasting, characteristics of the language learning situation.

(a) As Spolsky (1989) points out, the language learner can have exposure to and practice in two qualitatively different settings: the informal environment of the target language community or the formal environment of the classroom. The focus of the research reported in this article is on language learning in South African high school classrooms.

(b) Is the class an English class, or a class in which other subjects such as history or mathematics are being taught? This is an important distinction to make when considering the HL/English only question. The aims of teaching English in an English class are somewhat different from the aims of teaching Geography in a class where English is the medium of instruction. My research focuses on language choice in the English class.

(c) Is the English class one which follows the English First Language syllabus, or is it one which follows the English Second Language (ESL) syllabus? The aims of these two syllabi are different. Consequently, decisions about $\mathrm{HL}$ use in English first and second language classes would also be different. What complicates the matter here is the fact that first language classes are usually multilingual in the sense that they contain, to varying degrees, students who speak different home languages.

(d) If the class is an ESL class, do the learners in that class share the same $H L$ or is there more than one HL in the class? If there is more than one, questions regarding their use may be more difficult to answer. 
(e) Are English teachers English speakers, or are they speakers of other languages? And if they are the latter, do they make use of their HL (if it is the same as the students') when teaching?

(f) When discussing English only in the English classroom, are we discussing the teachers' use of the HL, or the students', or both? This is often not clear in the literature (e.g. see Atkinson, 1987; Kgomoeswana, 1993). The study discussed below focuses mainly on the students' use of the HL in English classes.

(g) When language learners use their $\mathrm{HL}$, is this use sanctioned or unsanctioned? In other words, have they been encouraged or instructed to use the HL?

(h) Both sanctioned and unsanctioned use of the HL could be task related or non-task related. For example, a case of task related, sanctioned use could be learners discussing, in the HL, set questions to a poem in small groups. A case of task-related, unsanctioned use of the HL could be learners using their HL to perform a role-play when they were specifically asked by the teacher to use English to complete the task. An example of non-task related use of the HL could be when learners use their HL to communicate about matters not related to classroom work, such as planning their weekend in class or gossiping about another student. This too could be sanctioned or unsanctioned. Of course, there may also be tasks which require only English to be used; for example, an information gap activity to develop conversation skills.

(i) Use of the HL could be controlled or uncontrolled. This means that, in cases of sanctioned HL use, it could be carefully planned and monitored, or left to run its own course. Calls for systematic use of the HL have come from Atkinson (1987), Faleni (1993) and Kharma \& Hajjaj (1990). It would be unwise to promote unreservedly the use of the HL in English classes, especially in the form of written policy statements.

(j) Is the HL used for language instruction, as implied in all the points above, or is it the topic of language work? In other words, does the HL itself become the focus of a language activity, perhaps in the form of a contrastive analysis?

(k) Using the HL and English in English classes does not necessarily mean that codeswitching is taking place. Paulston (1985:25) points out that 'codeswitching is a technical term in sociolinguistics, and it means a lot more than the occasional use of two languages.' People involved in the English only debate need to acknowledge this, and if they frame their arguments in terms of code-switching theory, they too should heed the warnings about a non-systematised approach to language choice and use in the classroom.

What follows is a report on an investigation into the perceptions of student teachers with regard to the issue of English only in the English classroom. Through their comments and ideas the eleven contextual factors discussed above will become more meaningful, and hopefully language teachers may then be able to make more informed decisions about the use of HL in their English classes. 


\section{THE STUDY: DATA COLLECTION AND ANALYSIS}

This study forms part of a larger study which explored the expectations of student teachers in their final year of study. All student teachers were planning to become English teachers. The aim of the study was to discover what expectations student teachers had of their future lives as English teachers in South Africa. The study reported here aims specifically to examine the ideas these student teachers have about the use of languages other than English in their future English classes. The focus is on the language choice of the students, rather than the teachers, although reference to the teachers' use of English and their own or their students' HL obviously cannot be left out of the arguments. Furthermore, the study is exploratory in nature and does not pretend to offer definitive answers to the question of HL use in the classroom. The responses of the student teachers serve merely to illuminate pertinent issues and to suggest topics for further investigation.

Questionnaires were distributed to five universities in the Eastern Cape, the Western Cape and Kwazulu Natal. 108 questionnaires were returned from the five universities $(35,17,30,21$ and 5 from each respectively), 95 of which were valid for the purposes of this study. Validity was determined on the basis of respondents having answered the relevant question; and secondly, on their being university students who were planning to become high school English teachers.

Of the 95 high school student teachers, 55 were English speakers and 40 were speakers of home languages other than English (HLOE). These respondents were reading for the Higher Diploma in Education, a post-graduate qualification, typically the fourth and final year of study before embarking on a teaching career.

I feel that examining the ideas of student teachers with regard to language choice in the classroom is useful since their own experiences of studying or learning English at school are still reasonably fresh in their minds. At the same time their opinions have not yet been influenced by actual classroom practice. Student teachers become a meaningful proportion of the teaching population once they take up their teaching jobs. Their views, therefore, are significant. This is not to say that investigating the using of English only issue from the perspectives of teachers (e.g. the survey mentioned by Auerbach, 1993) and the learners themselves is not important. Including student teachers merely helps to paint a broader picture.

The relevant, open-ended, question on the questionnaire was worded as follows:

'What are your ideas about students using their home language (if not English) in your English class?'

This was the last question of the questionnaire and was immediately preceded by questions concerning the respondents' views on the nature of the relationship they expected to have with their students and how they expected to deal with cultural differences in their classes. 
The responses were analyzed as follows:

(a) whether the respondents were planning to become high school or primary school English teachers.

(b) whether the respondents were English or HLOE speakers.

(c) whether the respondents believed that $\mathrm{HL}$ use in the English classroom should be Accepted Unconditionally, Accepted Conditionally or Not Accepted.

(d) comments or reasons to support their view were categorised thematically.

\section{THE STUDY: FINDINGS AND DISCUSSION}

In this section, a quantification of the attitudes of student teachers regarding the use of $\mathrm{HL}$ in English classrooms will be presented. Thereafter, their comments and rationale for their attitudes will be discussed.

\subsection{Attitudes to HL use}

Tables 1 indicates the high school student teachers' attitudes to the use of the $\mathrm{HL}$ in English classes.

Table 1 High school student teachers $(N=95)$ : Attitudes to students' use of the home language (HL) in English classes.

\begin{tabular}{||l|l|l|l|l||}
\hline $\begin{array}{l}\text { Student } \\
\text { Teachers }\end{array}$ & $\begin{array}{l}\text { Accept } \\
\text { Unconditionally }\end{array}$ & $\begin{array}{l}\text { Accept } \\
\text { Conditionally }\end{array}$ & Not Accept & TOTAL \\
\hline English & $4(7.3 \%)$ & $39(71.1 \%)$ & $12(21.8 \%)$ & 55 \\
\hline HLOE & $3(7.5 \%)$ & $9(22.5 \%)$ & $28(70 \%)$ & 40 \\
\hline TOTAL & $7(7.4 \%)$ & $48(50.5 \%)$ & $40(42.1 \%)$ & 95 \\
\hline
\end{tabular}

Of the 95 respondents only $7(7.4 \%)$ accepted the use of the HL unconditionally. This clearly illustrates a certain amount of cautiousness regarding the uninhibited, uncontrolled use of the HL, and reflects the thinking of the teachers in Kharma \& Hajjaj's (1990) study.

$48(50.5 \%)$ of the respondents also expressed reservations. They believe that there is a place in the English classroom for the HL, but only under certain conditions (these will be examined below). 40 of the 95 respondents (42.1\%) did not accept the use of the HL in English classes.

This is an alarmingly high number, especially when one considers:

(a) the findings of those involved in second language acquisition research which show, inter alia, that a 'benefit of using the $\mathrm{Ll}$ is that it reduces the affective barriers to English acquisition and allows for more rapid progress to or in ESL' (Auerbach, 1993:19). 
(b) the findings of research into code-switching in South African academic settings which indicate that code-switching is an aid to language learning (e.g. Adendorff, 1993; Kieswetter, 1995).

(c) the realities of the classroom which, from my own experience (Gordon \& Barkhuizen, 1994) and those of others (e.g. Peires, 1994), demonstrate that preventing the use of the $\mathrm{HL}$ in class is almost impossible.

(d) the new language in education policy in South Africa which stresses the equality of and respect for all South African languages, and which sees multilingualism as a resource and not as a problem (ANC, 1994; Forrest, 1994).

This means that 88 (92.6\%) respondents had some reservations about using the HL in English classrooms.

The situation is particularly interesting when the English and HLOE respondents are considered separately. Those who Accept Unconditionally from both groups are very similar in number. Numbers for the other two categories of opinion, however, are very different indeed. 28 of 40 (70\%) of the HLOE respondents do Not Accept the use of the HL in English classes, whereas only 12 of $55(21.8 \%)$ English HL speakers agree with the English only position. The numbers for Accept Conditionally are similarly reversed. One possible explanation for this could be that the HLOE student teachers may be more perceptive of the pedagogical needs of HLOE speakers: specifically, the need for English practice in English classes. Many HLOE learners in South Africa rarely get the chance to speak English outside the classroom, and so too inside the classroom if their teachers are also HLOE speakers who overuse the HL for instructional purposes. I would predict that many of the HLOE respondents have had such experiences, and consequently blame their own lack of proficiency in English on poor teaching and minimal practice. Their argument for more English in English classes is thus understandable in this context.

Another possible explanation may lie in the inherent power of English. English is possibly perceived to be the language which provides access to education, to jobs and to wealth. Consequently, its importance is reflected in the high number of respondents who promote its use uncompromisingly in the classroom.

\subsection{Rationale for attitudes}

In this section, the student teachers' ideas concerning students' use of the $\mathrm{HL}$ in English classes will be examined. I have placed the findings and my discussion of these together for ease of reference. When respondents read the question on the questionnaire, they all obviously had very different perceptions of an English class in action, and of the language choices which were being made in each of these classes. They no doubt saw English learners of varying levels of proficiency and saw different teachers in operation. In addition to this, the student teachers had different teacher education experiences depending on the university or college which they attended. Their ideas can, nevertheless, be categorised into common themes for the purpose of raising awareness amongst those involved in the fields of language teaching, language planning and language in education research. The common themes have been grouped under the relevant attitude (i.e. whether the respondent accepted the use of the $\mathrm{HL}$ conditionally, unconditionally, or not at all), and for the sake of interest, the number of times a particular theme was mentioned 
has been indicated. Often a particular respondent would refer to more than one theme, or give more than one reason for his or her opinion. In each case, all the points were noted and counted.

\subsubsection{High school student teachers (English speakers): $\mathbf{N}=55$}

Accept unconditionally $4(7,3 \%)$

Those respondents who accept the use of the HL unconditionally in the English classroom commented in the following ways:

A. Knowing students' $H L(2)$. Here the student teachers express a desire to be able to speak and understand their students' HL. One responded to the question: 'Absolutely, I wish I could speak a few! It's [the HL] all some of them have, especially at school.' The rationale here is no doubt that if the teachers could speak the students' HL they would then be able to make use of what the children bring to school more effectively for the sake of language instruction and learning.

B. Usefulness in class (1). Without giving details, this respondent feels that using the HL would be useful for everyone in the class. The respondent probably means in a pedagogical sense; an idea raised by many others. This will be discussed below (see $\mathrm{C}$, D, E, F, G, S).

\subsection{1(b) Accept conditionally $39(71,1 \%)$}

Typically respondents answered in the following way: 'Yes, I would accept the HL in my English class if ...' In other words, they believe that the HL is acceptable only under certain conditions, or they accept it with reservations. The following are some of their comments:

C. Facilitate understanding, expression and learning (19). This theme means that learners may use their $\mathrm{HL}$ if it will increase opportunities for learning and the communication of their ideas, and will allow them to gain a better understanding of English. For example, unknown English words could be translated into the HL (Paulston, 1985), or learners could ask questions in the HL. The high number (19) is expected here. There are many references to this facilitative, supportive function of the HL (e.g. see Adendorff, 1993; Auerbach, 1993; Kharma \& Hajjaj, 1990).

D. Encourage use of English for practice (10). What the respondents mean here is that they would allow the use of the HL in their classes, but at the same time would encourage the use of English. A high number was to be expected here. A commonsense assumption is that students come to an English class to learn English, and one way of doing that is to practise using the language (Kgomoeswana, 1993; Paulston, 1985). In the South African context, English classes may be the only time some students are exposed to English or get the chance to use English. This comment, therefore, makes good sense. At the same time, however, it does not mean that English should always be the only language used in every classroom (Atkinson, 1987).

E. Groupwork and informal interaction (8). The HL is acceptable for some forms of groupwork, such as when students share answers to an exercise or plan an oral presentation, and for informal, relaxed interaction. One respondent remarked that the 
$\mathrm{HL}$ is 'not acceptable in formal instructional interactions, for example, group feedback, talking about the subject matter. Informal interaction that occurs can be in any language.' This view has pedagogical support: 'The more the students can discuss something -- whether in English or in Xhosa (but they will probably code-switch) -- the more they will master the topic' (Peires, 1994:21). The feeling amongst respondents who mentioned this theme is that non-task related language use can also be in the HL. From an affective perspective this makes sense, and will be discussed below.

F. When problems arise (6). This represents a compensatory view of $\mathrm{HL}$ use in English classrooms. Respondents commented that the HL can be used 'for explanatory purposes only if English fails,' 'if they can't find the English words,' and 'only if they are absolutely unable to express themselves in English.' What is implied in these comments is that the use of English will be strongly encouraged, but HL will be accepted only when the need arises, a view also expressed in other research findings (Kharma \& Hajjaj, 1990; Yi An, 1985).

G. Affective factors (6). Respondents feel here that allowing the HL will result in the learners feeling more confident, more relaxed and comfortable in class, and will increase their morale. One respondent also feels that it will 'lead to a deeper enthusiasm' for learning English. Affective factors such as these are considered to be not only essential for language acquisition (Krashen, 1981, 1982), but also to ensure that learners enjoy their classes, experience a sense of security in an anxiety-free classroom environment (Auerbach, 1993), do not feel alienated from the classroom culture (Gordon \& Barkhuizen, 1994) and in fact stay in the class (Peirce, 1995).

H. English only for advanced students (4). These respondents feel that the HL should be accepted in lower proficiency level English classes, but not in more advanced classes. One stated, 'Advanced classes should be English only, taken that students have gone through the education system,' a point noted in other studies (e.g. Kharma \& Hajjaj, 1990). Another respondent believes that the HL should only be allowed in ESL classes and not in multilingually-composed classes following the English first language syllabus.

I. Respect for other languages (1). This politically correct response comes from a respondent who feels that she 'won't encourage it [HL use], but other languages must be respected.' One certainly could not fault her observation, but one might question what this statement in the context of an English classroom means.

\subsection{1(c) Not accept $12(21,8 \%)$}

J. Defeats purpose of an English class (7). The feeling here is that the purpose of English classes is to learn English. Therefore, only English should be used. A number of these respondents said that using the HL would be wasting opportunities to practise English and thus 'defeats the purpose of learning to communicate in English,' an observation related to themes $\mathrm{D}$ above and $\mathrm{Q}$ below. 
K. Teachers do not understand the home language (3). Because these respondents do not speak the HL of their prospective students, they feel that it should not be used in their classrooms: 'I do not want to hinder the learning process by being prescriptive, but, I only speak/understand English and Afrikaans. I would not understand any other languages.' These respondents seem not to have recognised the possible advantages of using learners to translate difficult concepts or vocabulary items for others in the class who are having particular difficulties.

L. $\quad$ No limited English proficiency students expected (1). This student teacher believes that she will not encounter any learners who 'barely speak any English' - an unlikely prospect in most South African high schools.

\subsubsection{High school student teachers (HLOE speakers): $N=40$}

4.2.2(a) Accept unconditionally $3(7,5 \%)$

M. At least students are participating (2). If leamers use the $\mathrm{HL}$, they are at least participating in classroom life. Themes C, D and Q are relevant here. However, one should perhaps heed the warning of teachers in Kharma \& Hajjaj's (1990:230) study who contend that: HL in the classroom increases expectations of more use of $\mathrm{HL}$, hinders fluency, destroys motivation, and distracts students.' 'Teachers should obviously not discourage participation, but should try to make use of students' participatory energy in order to foster more and appropriate English use.

N. Creates positive attitude towards English (1). This respondent means that because students will not feel pressurised to speak English, they will develop a more positive attitude towards the language. They will not see the language as being imposed on them, and will be able to make their own language choice decisions.

O. Will enrich the class (1). This respondent was not clear in what way the classroom would be enriched. However, one could assume that he or she means from a pedagogical, cultural-sharing point of view.

\subsection{2(b) Accept conditionally $9(22,5 \%)$}

Starting in this section, themes begin to recur. I shall not discuss them further, unless there is something specific which needs to be said about them.

C. Facilitate understanding, expression and learning (6).

D. Encourage use of English for practice (4). HLOE speakers may appreciate more fully the need for practice in English classrooms. However, they see that the HL can serve a purpose at times.

F. When problems arise (2). One respondent said, for example, 'I'm positive if the students get stuck while really trying hard to put message across - but I won't allow free use of the home language.' 
E. Groupwork and informal interaction (1). This respondent feels that 'they have to have practice to speak the language but in the case of group discussions whereby they want to express a certain idea but are having difficulties, I don't mind them using their mother tongue, as long as they report back in English.'

P. Only supervised use of $H L$ (1). This response hints at the idea of the controlled use of the HL discussed in my framework for the English only debate in the introduction. The respondent's comment is as follows: 'Students should be supervised when speaking other languages. Allowed only when necessary. They should not use it more than they use English. A little bit of it won't harm but if its use exceeds English then I'll forbid it.' Faleni (1993) considers the basic requirements for the effective use of code-switching in the classroom to be conscious use, systematic use and purposeful use. The same could possibly apply to the use of the HL in English classes.

Q. Practice in English needed (8). The motivation for practice is the same as that for theme $\mathrm{D}$. The difference, however, is that respondents will not allow the use of the HL at the same time. One of the respondents said, 'I will tell them that they know their mother tongue very well and they should practise what they do not know until they improve in it.'

R. Retards progress in English (7). This is the converse of themes D and Q; that is, if the $\mathrm{HL}$ is used, less practice in English will take place and progress will be impeded. This idea was succinctly expressed by one of the respondents: No way! That is what my high school teachers did to me and it had its negative effects. I think the more you try to speak English, the more you master it.'

S. Learn from mistakes (4). The argument here is that if learners are forced to speak English, they will no doubt make errors. These errors can then be identified by the teacher and corrected. Through this trial and error process, learners acquire the language; very much like the approach advocated by the communicative language teaching method (Richard \& Rodgers, 1986).

T. No compromise (3). These respondents do not give reasons for not accepting the HL in English classes, but are adamant that no HL will be heard in their classes. For example, this attitude is expressed in the following comment: 'I'll give them orders to speak English. Failure to do so will render them punished.' This authoritarian, blinkered perspective is dangerous in that it goes against all the positive aspects of accepting the $\mathrm{HL}$ in the English class discussed in this article. Furthermore, it forcefully denies the learners the right to use their own language, and thus reinforces the existing unequal relations of power between teachers and their learners (for similar arguments see Auerbach, 1993; Fairclough, 1989).

N. Creates positive attitude towards English (2). 
U. English is medium of instruction (2). In many South African high schools English is the medium of instruction for all subjects taught (this practice could very possibly change since new language in education policies are currently being devised). These respondents are either simply obeying policy by suggesting that English be used for instructional purposes in the English class, or they feel that the English class should serve the other subjects by ensuring that English is taught and learned adequately for academic purposes.

V. Share rationale for policy (2). These two respondents feel that they should explain to their students why they will not allow the HL to be used in their classes; that is, that 'they won't progress any further if they don't practise even a single sentence in English.' One of the respondents said that she will 'use diplomacy' to convince them of the merits of using only English. This sharing of the rationale behind the policy may be a good idea. Perhaps they could go one step further and negotiate a policy of their own, as suggested by Auerbach (1993:24):

Rather than the teacher making the decision for the students (either for or against L1 use), the question can be posed to students for reflection and dialogue. As such, the issue itself can become content for language and literacy work. Students can discuss when it is and isn't helpful to use the L1 in English acquisition. After considering the advantages and disadvantages of L1 versus L2 use and the functions of each in different contexts, students can establish their own rules for the classroom.

\section{CONCLUSION}

The student teachers who responded to the questionnaire in this study considered the teaching context in which they would soon find themselves and then made a decision with regard to the role that the $\mathrm{HL}$ would or would not play in their English classes. Much of what they have to say appears to be based on commonsense assumptions about language learning and teaching, and their arguments are framed very much in pedagogical terms. The respondents have spent many years in schools as students (and language learners), they have been involved in teacher education programmes, and they are on the brink of starting their careers as English teachers in South African high schools. However much we might feel that their perceptions are unfounded or unreflective of recent research findings, they cannot be ignored.

However, this does not mean that the search for an answer to the English only question should , be abandoned. At the moment there appears to be no answer. There are so many language teaching contexts in South Africa; their similarities and differences need to be explored. People are talking at cross-purposes. In addition to this, researchers, policy makers and teachers are still not talking enough to each other. The danger lies in the possibility of approving languagein-education policy statements which are not based on a thorough examination of the issues involved in using or rejecting the $\mathrm{HL}$ in English classes. The contextual factors which I presented at the beginning of this article provide a start. What follows are recommendations for further investigation and consideration. 
Perhaps we should move beyond the pedagogical parameters of the English only concept. Auerbach (1993; see also Peirce, 1995), for instance, points out that language teaching is a political matter. As such, ideological as well as pedagogical issues are central to any decisions made about English only. Such ideological issues include the relations of power in the classroom between teachers and students. Who makes the decisions about which languages can and cannot be used? These 'relations of power and their affective consequences are integral to language acquisition' (Auerbach, 1993:16). What about the societally determined values attributed to the languages in the classroom? In spite of recent language policy reforms, English is still perceived to be a more powerful language than any other in South Africa. It is the perceived language of progress and the language of success (Titlestad, 1996). The consequences for language choice in the classroom, from the perspective of teachers and students (and their parents), are obvious. Besides carrying wider social meaning; 'languages express the identity of the groups which use them, and reflect the value system of their users' (Adendorff, 1993:18-19). Group and individual feelings about specific languages must also, therefore, be taken into account. It would be useful for further research endeavours to investigate, for example, the place of English as a $\mathrm{HL}$ in Xhosa or Afrikaans second language classrooms.

The Interim Core Syllabus for English Second Language (1995/96) in South African schools requires adherence to the Communicative Language Teaching (CLT) approach. The aim, it states, is 'to enable pupils to communicate successfully for personal, social, educational and occupational purposes' (1995:3). Considering firstly, that CLT promotes the functionally appropriate use of language -- and the fact that the approach allows for 'the judicious use of native language' (Richards \& Rodgers, 1986) -- and secondly, that the reality of communicative events outside the classroom contain constant alternation between languages, perhaps it is time to plan for and monitor more closely language choice decisions made in English classes.

What factors should be taken into account when planning for HL use? I have argued above that $\mathrm{HL}$ is going to be used in the classroom whether teachers forbid it or not. It seems sensible, therefore, to make the effort to consciously shape and monitor its use; in other words, there should be some systematic control over the quality and quantity of HL use (see arguments for the systematic and purposeful use of the HL, and warnings for avoiding its overuse in Atkinson, 1987, and Kharma \& Hajjaj, 1990). As discussed in theme V ('share rationale for policy'), perhaps one way of establishing classroom rules for $\mathrm{HL}$ use could be for all members of the class to negotiate these.

The limitations of the research presented in this article are obvious: one cannot draw firm conclusions from responses to one question on a questionnaire. Furthermore, the respondents come from different educational and linguistic backgrounds, and attend various institutions of higher learning, each with their own approach, both ideologically and pragmatically, to teacher education. The purpose of this study, as I have explained above, is to highlight some of the issues, and to elaborate on the contextual factors discussed in the list I presented in the introduction. These factors influence decision making regarding language choice in the classroom. Ethnographic work, especially in the form of in-depth interviews and extended classroom observation, needs to be conducted in schools and teacher education programmes. Researchers, I feel, would also benefit enormously by talking to the language learners themselves. 
Finally, it would seem to be true that very little attention is given to the role of the HL in English teaching and learning in teacher preparation courses. When the topic emerges, it is usually within the areas of second language acquisition theory and ESL teaching methodology. It should, however, be linked to policy debates and socio-political implications. Doing so should enable teachers to make more informed decisions.

\section{REFERENCES}

ADENDORFF, R. 1993. Code-switching amongst Zulu-speaking teachers and their pupils: Its functions and implications for teacher education. Southern African Journal of Applied Language Studies, 2(1): 3-26.

AFRICAN NATIONAL CONGRESS (ANC). 1994. A policy framework for education and training. Johannesburg, South Africa: ANC.

ATKINSON, D. 1987. The mother tongue in the classroom: a neglected resource? English Language Teaching Journal, 41(4): 241-247.

AUERBACH, ER. 1993. Reexamining English only in the ESL classroom. TESOL Quarterly, 27(1): 9-32.

DEPARTMENT OF EDUCATION. 1995. Interim core syllabus for English second language: Standards 8,9 and 10.

FAIRCLOUGH, N. 1989. Language and Power. London: Longman.

FALENI, T. 1993. The case for codeswitching. ELTIC Reporter, 17(2): 11-12.

FORREST, F. 1994. A language curriculum framework for compulsory general education. Johannesburg: Centre for Education Policy Development.

GORDON, F AND GP BARKHUIZEN. 1994. Alienation and conflict in an open primary school: a multilingual setting. Southern African Journal of Applied Language Studies, 3(1): 60-76.

HEUGH, K. 1992. Enshrining elitism: The English connection. Language Projects Review, 7(3): 12.

HEUGH, K. 1993. Tongues untied: Multilingual models. Bua!, 8(3): 29-30.

THE INTERIM CORE SYLLABUS FOR ENGLISH SECOND LANGUAGE SCHOOLS. $1995 / 6$.

KGOMOESWANA, VN. 1993. The case against codeswitching in multilingual classrooms. ELTIC Reporter, 17(2): 13-16. 
KHARMA, NN AND AH HAJJAJ. 1990. Use of the mother tongue in the ESL classroom. International Review of Applied Linguistics, 27: 223-235.

KIESWETTER, A. 1995. Code-switching Amongst African High School Pupils. Johannesburg: University of the Witwatersrand.

KRASHEN, S. 1981. Second Language Acquisition and Second Language Learning. Oxford: Pergamon.

KRASHEN, S. 1982. Principles and Practice in Second Language Acquisition. Oxford: Pergamon.

PAULSTON, CB. 1985. Significant features of bilingual instruction: second language acquisition in school settings. Unpublished manuscript.

PEIRCE, BN. 1995. Social identity, investment, and language learning. TESOL Quarterly, 29(1): 9-31.

PEIRES, M-L. 1994. Code-switching as an aid to L2 learning. Southern African Journal of Applied Language Studies, 3(1): 14-22.

RICHARDS, JC AND TS RODGERS. 1986. Approaches and Methods in Language Teaching. Cambridge: Cambridge University Press.

SPOLSKY, B. 1989. Conditions for Second Language Learning. Oxford: Oxford University Press.

TITLESTAD, P. 1996. LANGED and tertiary education. The English Academy of Southern Africa: Newsletter, 16: 4-5.

YI AN, W. 1985. Code-mixing by English-Chinese bilingual teachers of the People's Republic of China. World Englishes, 4(3): 303-317. 